\title{
Assessment of left ventricular function by single plane cineangiographic volume analysis
}

\author{
K. Chatterjee ${ }^{1}$, M. Sacoor, G. C. Sutton, and G. A. H. Miller \\ From the Cardiac Department, Brompton Hospital, London S.W.3
}

Single plane cineangiography, either in the anteroposterior or in the right anterior oblique projection, can be used to determine left ventricular volumes. Volumes so obtained showed good agreement with those reported by others using biplane techniques. Ejection fraction and ejection rate derived from such volumes were normal in patients with mitral stenosis and with chronic compensated pressure and volume overloads, but were significantly reduced in patients with

- cardiomyopathy. Unlike ejection fraction and ejection rate, left ventricular end-diastolic pressure was not found to be a sensitive index for differentiating patients with and without left ventricular dysfunction.

Volumetric analysis of the left ventricle by serial biplane angiography is now an established method for quantitative assessment of left ventricular function (Dodge et al., 1966; Dodge and Baxley, 1969; Arvidsson, 196r; Miller, Kirklin, and Swan, 1965; Kennedy et al., 1968). This technique has the disadvantage that infrequent film exposures necessitate construction of a composite volume curve, and volume changes so measured represent an average of several cardiac cycles. Biplane cineangiography (Chapman et al., 1958; Vogel, Horgan, and Strahl, 1970), on the other hand, permits analysis of beat-to-beat volume changes and assessment of reproducibility; moreover, the greater number of film exposures reduces the chance of inaccurate estimation of end-systolic and end-diastolic volumes. In clinical practice, single plane cineangiography is more commonly available for assessment of valve or myocardial function. Since others (Sandler et al., 1965; Sandler and Dodge, 1968; Dodge et al., I966; Hermann and Bartle, 1968) have shown good correlation between volumes calculated by serial single plane and serial biplane angiography the possibility exists of utilizing single plane cineangiography during routine cardiac catheterization for left ventricular volume analysis. Indeed several workers (Carlisle et al., I964; Moore, 1965; Greene et al., 1967; Hermann, Singh, and Dammann, 1969; Falsetti et al., 1970) have employed cineangiography in the Received 17 September 1970.

1 Present address: Department of Cardiology, CedarsSinai Medical Center, Cedars of Lebanon Hospital Division, Box 54265, Los Angeles, Calif. 90029, U.S.A. right anterior oblique projection for this purpose. In the present study, the relation between left ventricular volumes calculated by single plane cineangiography in the anteroposterior and in the right anterior oblique projections has been investigated, as has the relation between known and angiographically calculated left ventricular volumes. Once the validity of single plane (anteroposterior) cineangiographic calculations of left ventricular volume had been established it became possible to investigate left ventricular function employing two indices, the ejection fraction and the ejection rate, derived from left ventricular volume measurement. This communication also reports the use of these indices to investigate left ventricular function in patients with no cardiac abnormality as compared with others with mitral stenosis, chronic pressure or volume load of the left ventricle, or left ventricular cardiomyopathy.

\section{Patients}

Forty-three patients were studied ( 18 female, 25 male, age range 4 to 68 years). On clinical, radiological, electrocardiographic, and haemodynamic findings they were divided into the following groups.

Group I: Normal (7 patients) Three were investigated for atypical chest pain; two had suspected minor pulmonary embolism, one a mediastinal shadow, and one idiopathic dilatation of the pulmonary artery. Detailed investigation, including conventional cardiac catheterization, did not reveal any significant abnormality of the cardiovascular system in any patient.

Group 2: Mitral stenosis (4 patients) All 
patients had isolated mitral stenosis; three were in sinus rhythm and one had atrial fibrillation, but with a slow ventricular rate. The mean mitral valve gradient, determined by recording simultaneous left ventricular diastolic pressure and pulmonary artery 'wedge' pressure, ranged from 5 to $20 \mathrm{mmHg}$ at rest. All were receiving digitalis.

Group 3: Compensated pressure overload (6 patients) Five patients had aortic valve stenosis with peak systolic gradients ranging from 50 to $130 \mathrm{mmHg}$, while one had fixed membranous subaortic stenosis (gradient $65 \mathrm{mmHg}$ ). None had significant aortic regurgitation. All were in sinus rhythm and none was digitalized at the time of study. As no patient in this group had any clinical evidence of heart failure (raised jugular venous pressure, peripheral oedema, paroxysmal nocturnal dyspnoea, exertional dyspnoea or radiological pulmonary congestion or cardiac enlargement), they were regarded as having compensated pressure overload.

Group 4: Compensated volume overload (9 patients) Six patients had severe aortic regurgitation as judged by aortic cineangiography. In none was there any significant aortic valve gradient. Three patients had mitral regurgitation; in two regurgitation was severe and in one it was moderate, as judged by left ventricular cineangiography. Mitral regurgitation was due to ruptured chordae in two patients and to rheumatic heart disease in one patient. All patients in this group were in sinus rhythm and only one patient was receiving digitalis. No patient was in clinical heart failure at the time of study; these patients were therefore regarded as having compensated volume overload.

Group 5: Cardiomyopathy (7 patients) All patients had both clinical and radiological cardiomegaly, all were in heart failure and were digitalized at the time of study. None had any significant valve lesion and all were thought to have primary myocardial disease of unknown aetiology, though coronary artery disease was not excluded as selective coronary arteriography was not undertaken.

Group 6: Homograft replacement of mitral valve (Io patients) All had cineangiography performed in both anteroposterior and right anterior oblique projections. In the present study, data obtained from these patients were only used to compare left ventricular volumes calculated in the two projections. The results of volumetric analysis of left ventricular function in these patients have been reported elsewhere (Sutton, Chatterjee, and Miller, 1971).

\section{Method}

Cineangiography was performed at a film speed of 35 frames $/ \mathrm{sec}$. Contrast medium, ${ }^{1}$ I to $1 \cdot 5$ $\mathrm{ml} / \mathrm{kg}$ body weight, was injected either into the ${ }^{2}$ Sodium, calcium and magnesium metrizoate (Triosil ( $75^{\prime}$ '). Glaxo Laboratories Ltd., Greenford, Middlesex. main pulmonary artery or, in a few patients, into the aortic root or the left ventricle. In all patients left ventricular or systemic arterial pressure and a standard lead electrocardiogram were recorded simultaneously to exclude significant haemodynamic alterations as a result of angiography. Correction for image magnification and distortion from non-parallel $x$-rays was performed according to the method of Greene et al. (1967) by filming a metal grid of $1 \mathrm{~cm}$ squares placed at the midchest level of the patient. The outline of the left ventricle was traced from each cine frame and the planimetered area and longest measurable length were determined (Dodge et al., 1960, 1966; Greene et al., 1967). After correcting all measurements for image magnification left ventricular volumes were calculated by the arealength method of Dodge et al. (1966), using an ellipsoidal reference figure.

The correlation between the actual volume and the calculated volume in the anteroposterior projection was determined from observations made in five barium-filled postmortem hearts. Each heart was suspended in a position approximately corresponding to that of a living heart in the anteroposterior projection. A known increment of barium sulphate paste was injected and a short run of cine exposures made at each increment of volume. The calculated volumes by this method in the anteroposterior projection underestimate the actual volume (Fig. I). Hence, calculated volumes in all patients were corrected for this underestimation according to the regression equation $\mathrm{V}=\mathrm{r} \cdot 477 \mathrm{~V}^{1}-4 \cdot 40$ (where $\mathrm{V}=$ actual volume and $\mathrm{V}^{1}=$ calculated volume in $\mathrm{ml}$ ). All estimated volumes were also corrected for body surface area and were expressed in $\mathrm{ml} / \mathrm{m}^{2}$.

FIG. I Comparison between measured volumes by single plane cineangiography in anteroposterior projection $\left(V^{1}\right)$ and actual volume $(V)$ of barium sulphate injected in postmortem hearts. Measured volume underestimates the actual volume.

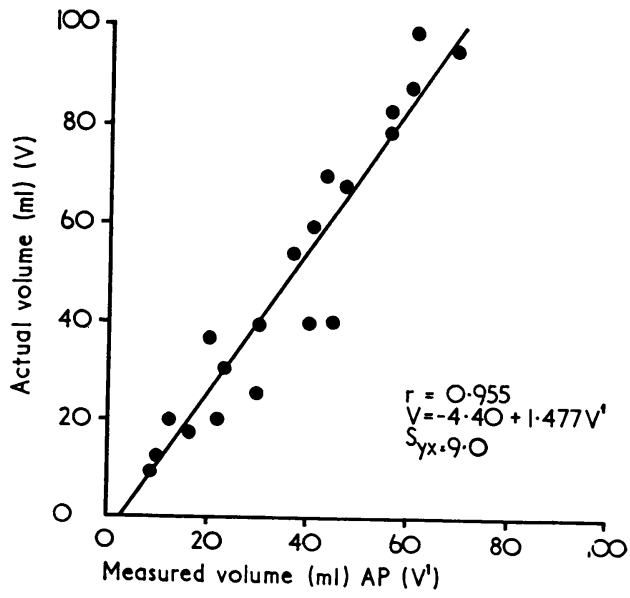


All volume calculations were performed by computer, and for each patient a volume curve covering several cardiac cycles was obtained from which the end-diastolic volume and the endsystolic volume were read directly (Fig. 2). The total left ventricular stroke volume was obtained by subtracting the end-systolic from the enddiastolic volume and the ratio of left ventricular stroke work to end-diastolic volume gave the ejection fraction. By drawing a tangent on the ejection portion of the volume curve the rate of ejection in $\mathrm{ml} / \mathrm{sec}$ was calculated. As the rate of ejection is dependent, not only on the contractile state, but also on the size of the heart, it was corrected for this factor by dividing it by the enddiastolic volume (normalized ejection rate) and was expressed in vol/sec (Hood, Rackley, and Rolett, 1968a). Left ventricular end-diastolic presure was measured immediately after the ' $a$ ' wave when this was clearly visible, and where no ' $a$ ' wave existed, at $0.05 \mathrm{sec}$ after onset of the QRS (Braunwald, Fishman, and Cournand, 1956).

\section{Results}

The correlation between the actual volumes and calculated volumes in the anteroposterior projection from observations in barium-filled hearts is shown in Fig. I. Though there was excellent correlation $(r=0.955)$, the calculated volume underestimated the actual volume. Hence, the calculated volumes have been corrected for this underestimation as described above.

Comparison between calculated volumes in the anteroposterior and right anterior oblique projections (Group 6, Fig. 3) indicated that volumes calculated in the same patient in the latter projection were considerably larger than those in the former projection. ${ }^{1}$ Despite this difference in estimated volumes in the two projections, the ejection fraction in the same patient remained practically unchanged (Fig. 4) suggesting that, for calculation of ejection fraction by single plane cineangiography, either projection could be employed.

Left ventricular volume data obtained by single plane cineangiography in the anteroposterior projection in 33 patients (Groups I to 5) are summarized in Table $\mathrm{I}$. The enddiastolic volume in normal controls (Group I, mean $70 \pm 17$, range 54 to $108 \mathrm{ml} / \mathrm{m}^{2}$ ) was not significantly different from patients with mitral stenosis (Group 2, mean $69 \pm 18$, range 5I to $88 \mathrm{ml} / \mathrm{m}^{2}$ ) or with compensated pressure

\footnotetext{
1 When changes in corresponding planimetered areas and measured major axes in the two projections were compared, the percentage increase in area was relatively more than the percentage increase in the major axis when the patient was rotated from the anteroposterior to the right anterior oblique projection, accounting for the larger calculated volume in the latter projection.
}

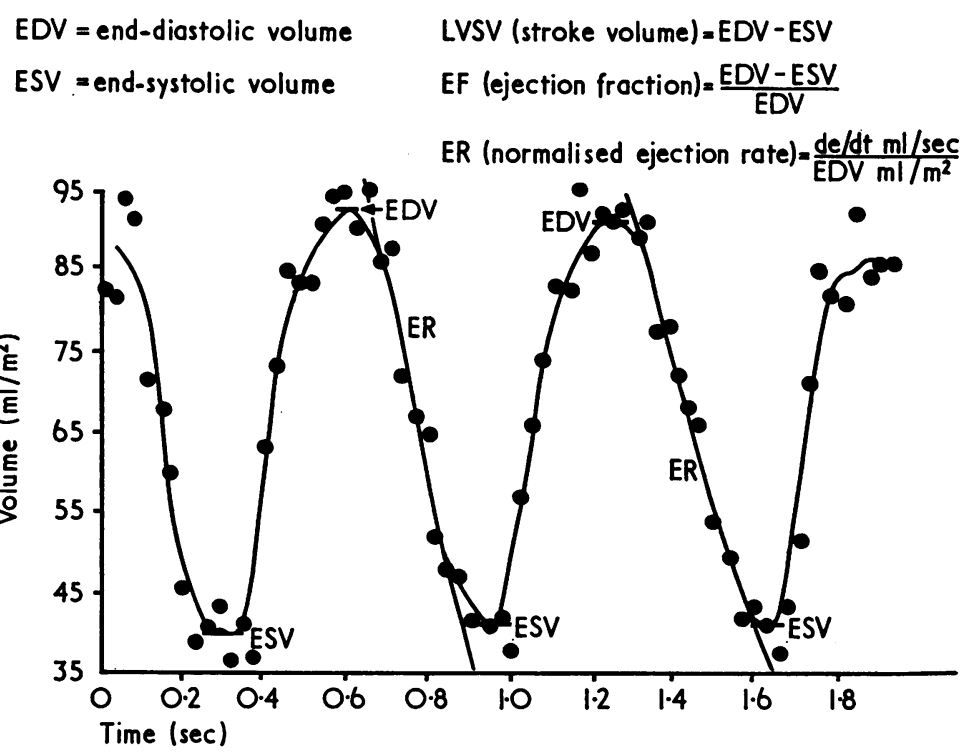

FIG. 2 A typical non-composite volume curve as obtained by computer analysis showing beatto-beat reproducibility.

overload (Group 3, mean $74 \pm 18$, range 53 to $93 \mathrm{ml} / \mathrm{m}^{2}$ ). It was significantly greater in patients with cardiomyopathy (Group 5, mean $167 \pm 28$, range 133 to $206 \mathrm{ml} / \mathrm{m}^{2}$ ) and, as would be expected, in those with compensated volume overload (Group 4, mean $172 \pm 58$, range 130 to $308 \mathrm{ml} / \mathrm{m}^{2}$ ) (Fig. 5). The angiographically determined left ventri-

FIG. 3 Comparison between calculated endsystolic and diastolic volumes in Io patients (Group 6) by single plane cineangiography in anteroposterior $(A P)$ and right anterior oblique $(R A O)$ projections. Volumes in right anteroposterior overestimate volumes in anteroposterior projection.

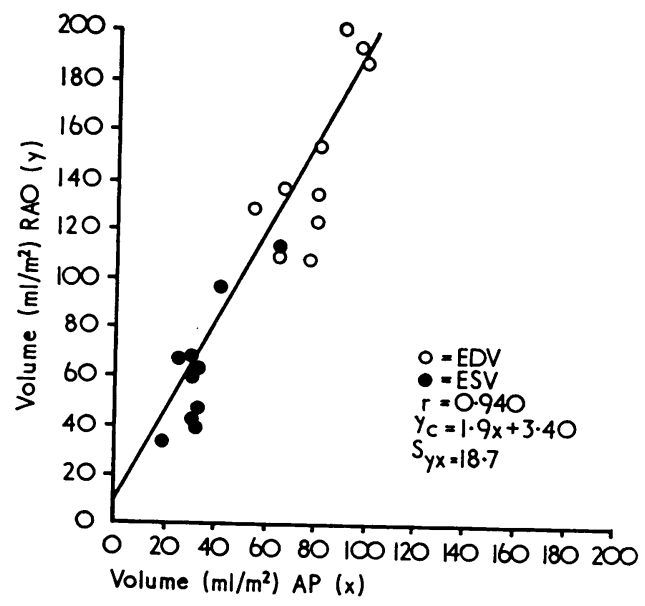




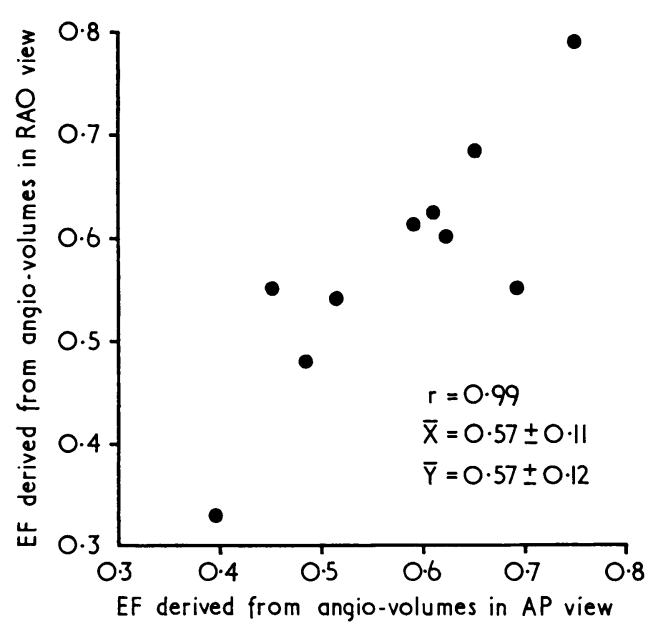

FIG. 4 Ejection fraction in 10 patients (Group 6) derived from calculated volumes in anteroposterior and right anterior oblique projections. The ejection fraction remains unchanged with change of projection.

cular stroke volume in normals (Group I, mean $49 \pm 10 \mathrm{ml} / \mathrm{m}^{2}$ ) was not significantly different from that in patients with mitral stenosis (Group 2, mean $5 \mathrm{I} \pm \mathrm{II} \mathrm{ml} / \mathrm{m}^{2}$ ) or with compensated pressure overload (Group 3 , mean $58 \pm 17$ ). In patients with compensated volume overload (Group 4) the left ventricular stroke volume was, as expected, higher (mean $106 \pm 35 \mathrm{ml} / \mathrm{m}^{2}$ ) and was slightly reduced in patients with cardiomyopathy (Group 5, mean $37 \pm 8 \mathrm{ml} / \mathrm{m}^{2}$ ) (Fig. 6).

The ejection fraction in normal subjects was $0.70 \pm 0.03$. In patients with mitral stenosis it was $0.75 \pm 0.03$ and in patients with compensated pressure overload $0.75 \pm 0.06$. A few patients with mitral stenosis or aortic stenosis had 'supernormal' ejection fractions (Fig. 7) due to smaller end-systolic volumes but normal end-diastolic volumes. The patients with compensated volume overload had a slightly lower ejection fraction (mean $0.6 \mathrm{I} \pm$ 0.06 ), but the difference was not significant

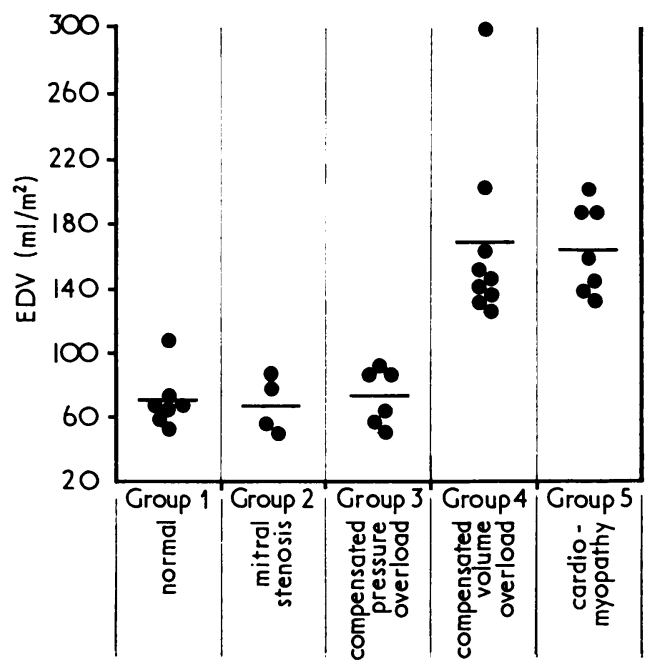

FIG. 5 End-diastolic volumes in patients in Groups I to 5. Mean value for each group is shown by horizontal line. End-diastolic volume is raised only in patients with compensated volume overload (Group 4) and cardiomyopathy (Group 5).

as compared with normal subjects. In contrast, patients with cardiomyopathy had a very low ejection fraction (mean $0.22 \pm 0.05$ ) and the difference as compared with normals was highly significant $(P<0.001)$.

The normalized ejection rate (Fig. 8) in normal controls (Group I) was $3.24 \pm 0.86$ $\mathrm{vol} / \mathrm{sec}$ (range 2.08 to $4.59 \mathrm{vol} / \mathrm{sec}$ ), and it was similar in all other groups except those with cardiomyopathy who had a significantly $(\mathrm{P}<0.00 \mathrm{I})$ lower value ( $\mathrm{I} .09 \pm 0.47$, range 0.66 to $\mathrm{I} \cdot 3 \mathrm{I} \mathrm{vol} / \mathrm{sec})$. There was a good correlation $(r=0.814)$ between ejection fraction and normalized ejection rate and both were significantly low only in patients with cardiomyopathy.

The left ventricular end-diastolic pressure measured in 32 of the 33 patients was not found to be a sensitive index in differentiating

TABLE I Left ventricular volume data in 33 patients

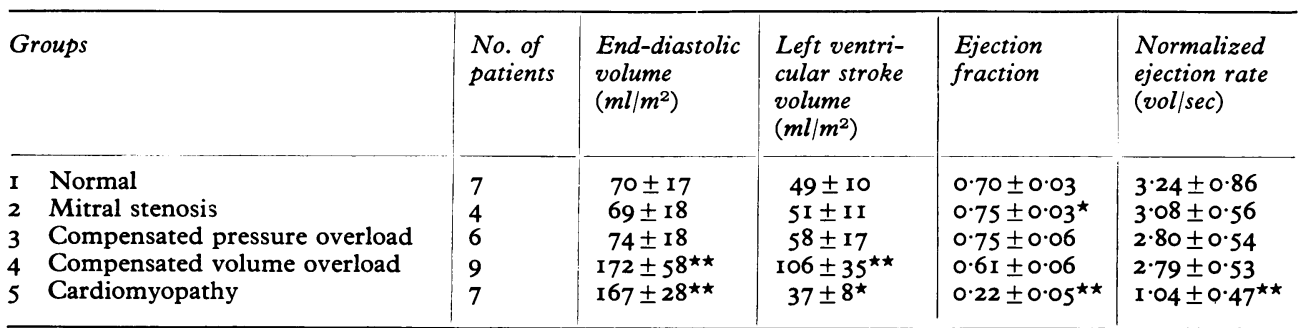

Significance as compared with normals: ${ }^{\star}=\mathrm{P}<0.05 .{ }^{\star} \star \mathrm{P}<0.001$. 


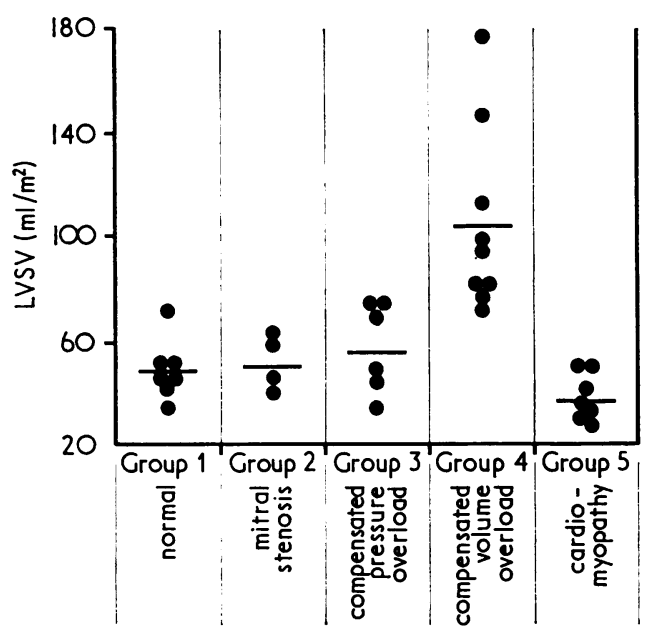

FIG. 6 Left ventricular stroke volume in $\mathrm{ml} / \mathrm{m}^{2}$ in Groups I to 5. Mean values are shown by horizontal lines. Left ventricular stroke volume is significantly increased only in Group 4.

between patients with and without left ventricular dysfunction; thus there was no correlation between left ventricular end-diastolic pressure and ejection fraction on the one hand $(r=0.459)$, or the end-diastolic volume $(r=0.317)$.

\section{Discussion}

The data obtained in this study in different groups of patients are very similar to those

\section{FIG. 7 Analysis of ejection fraction in} Groups I to 5. Mean values are shown by horizontal lines. The ejection fraction is significantly reduced in patients with cardiomyopathy (Group 5).

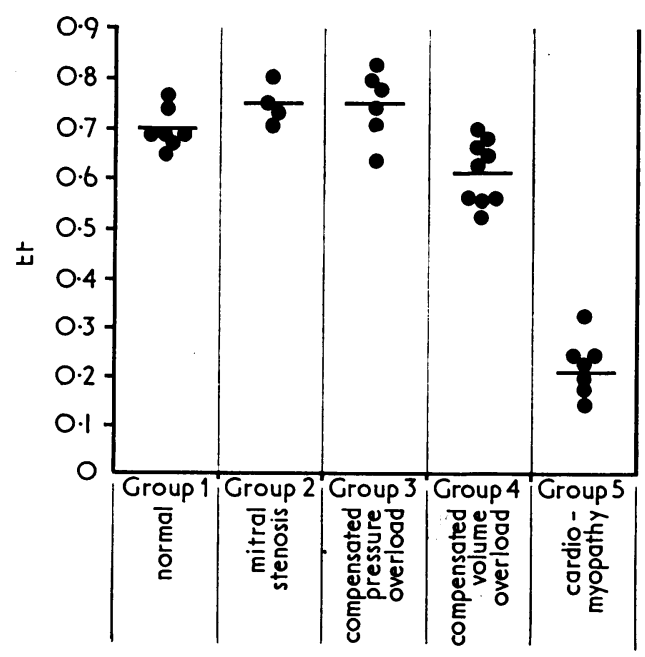

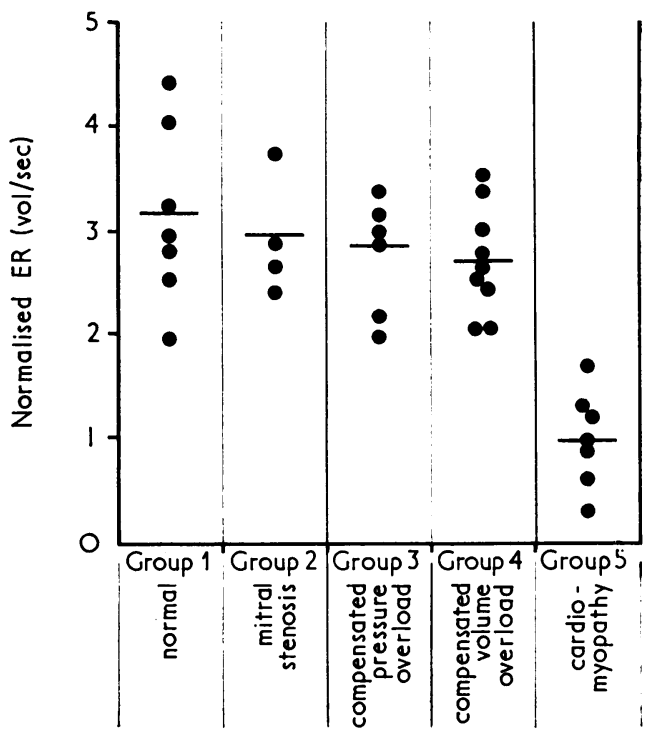

FIG. 8 Normalized ejection rate in vol/sec in Groups I to 5. Mean values are shown by horizontal lines. Ejection rate is significantly reduced in patients with cardiomyopathy (Group 5).

previously reported (Miller and Swan, 1964; Miller et al., 1965; Sanmarco and Bartle, 1964; Kennedy et al., 1966, 1968; Hood et al., I968b; Hermann et al., 1969). Thus, while the end-diastolic volume was increased in response to a chronic volume overload, the ejection fraction remained normal, suggesting that in these patients myocardial function was unimpaired. In contrast, the increase in end-diastolic volume in patients with cardiomyopathy was not associated with a corresponding increase in left ventricular stroke volume resulting in a low ejection fraction. This low ejection fraction characterizes impaired myocardial function (Dodge et al., 1966; Dodge and Baxley, 1968; Jones et al., 1964; Miller and Swan, 1964; Miller et al., 1965; Bunnell, Grant, and Greene, 1965; Grant, Greene, and Bunnell, 1965; Bartle, Sanmarco, and Dammann, I965; Hood et al., I968b).

The rate of ejection, when corrected for heart size, was also found to be a useful index of left ventricular function, confirming the findings of Hood et al. (1968a). Only patients with cardiomyopathy had a significantly low normalized ejection rate; all other patients (mitral stenosis, compensated pressure overload, and compensated volume overload) had values within the normal range. There was a good correlation between ejection fraction and normalized ejection rate, and both were 
TABLE 2 Comparison of calculated volumes in normal subjects by single plane cineangiography in AP projection with those derived by other angiographic methods

\begin{tabular}{|c|c|c|c|c|c|}
\hline Authors & $\begin{array}{l}\text { Angiographic } \\
\text { method }^{\star}\end{array}$ & $\begin{array}{l}\text { End-diastolic } \\
\text { volume } \\
\left(\mathrm{ml} / \mathrm{m}^{2}\right)\end{array}$ & $\begin{array}{l}\text { End-systolic } \\
\text { volume } \\
\left(\mathrm{ml} / \mathrm{m}^{2}\right)\end{array}$ & $\begin{array}{l}\text { Left ventricu- } \\
\text { lar stroke } \\
\text { volume } \\
\left(\mathrm{ml} / \mathrm{m}^{2}\right)\end{array}$ & $\begin{array}{l}\text { Ejection } \\
\text { fraction }\end{array}$ \\
\hline $\begin{array}{l}\text { Arvidsson (196r) } \\
\text { Miller and Swan (1964) } \\
\text { Sanmarco and Bartle (1964) } \\
\text { Moore (1965) } \\
\text { Kennedy et al. (1966) } \\
\text { Arvidsson (1966) } \\
\text { Hood et al. (1968b) } \\
\text { Hermann et al. (1969) } \\
\text { Falsetti et al. (1970) } \\
\text { Present study (1970) }\end{array}$ & $\begin{array}{c}\text { Biplane serial } \\
\text { Biplane serial } \\
\text { Biplane serial } \\
\text { Single plane } \\
\text { cine; RAO } \\
\text { Biplane serial } \\
\text { Biplane serial } \\
\text { Biplane serial } \\
\text { Single plane } \\
\text { cine; RAO } \\
\text { Single plane } \\
\text { cine; RAO } \\
\text { Single plane } \\
\text { cine; AP }\end{array}$ & $\begin{array}{l}85 \\
85 \pm 11 \cdot 65 \\
80 \pm 10 \\
\\
70 \pm 20 \\
72 \\
79 \cdot 3 \pm 4 \cdot 4 \\
70 \pm 16\end{array}$ & $\begin{array}{l}20 \\
27 \cdot 8 \pm 2 \cdot 5\end{array}$ & $\begin{array}{l}56 \pm 8 \cdot 9 \\
55 \pm 7 \\
45 \pm 13\end{array}$ & $\begin{array}{l}0.67 \\
0.67 \pm 0.08 \\
0.78 \pm 0.04 \\
0.67 \pm 0.08 \\
0.72 \\
0.665 \pm 0.30 \\
0.60 \pm 0.08 \\
0.71 \pm 0.17 \\
0.70 \pm 0.03\end{array}$ \\
\hline
\end{tabular}

$\star \mathrm{RAO}=$ right anterior oblique $\mathrm{AP}=$ anteroposterior.

equally sensitive in differentiating patients with and without left ventricular dysfunction.

In contrast, left ventricular end-diastolic pressure was not found to be a useful index of left ventricular function. In some patients with cardiomyopathy end-diastolic pressure was normal, while in some without clinical heart failure it was raised. Nor was there any correlation between end-diastolic pressure and the ejection fraction or normalized ejection rate. These findings support the view that left ventricular end-diastolic pressure is not a reliable index of left ventricular function (Braunwald and Ross, r963).

Though volumes calculated by single plane cineangiography in the anteroposterior projection somewhat underestimate the actual volume, an excellent correlation was found between the two. The calculated volumes corrected for this underestimation were in close agreement with those reported by other workers who have used biplane angiography (Arvidsson, 196I, 1966; Miller and Swan, 1964; Sanmarco and Bartle, 1964; Kennedy et al., I 966; Hood et al., I968b) or single plane cineangiography in the RAO projection (Moore, 1965; Hermann et al., 1969; Falsetti et al., 1970) (Table 2). There was also an excellent correlation between volumes calculated by single plane cineangiography in the right anterior oblique and in the anteroposterior projections in the same patients, though the values were consistently larger in the right anterior oblique projection. This overestimation in the right anterior oblique projection was also found in postmortem heart studies (Greene et al., 1967). Despite these variations in calculated volumes with change of projection the ejection fraction in the same patient remained practically unchanged. Indeed ejection fraction derived from calculated volumes by single plane cineangiography in the anteroposterior projection in this study is very similar to that reported by Falsetti et al. (1970) who employed cineangiography in the right anteroposterior proejction (Table 2). These findings suggest that for routine clinical practice estimation of the ejection fraction, unlike end-diastolic pressure, can provide useful information about left ventricular function in patients with various cardiac disorders in the chronic state. It can be easily derived from volume analysis by single plane cineangiography during routine cardiac catheterization, and either the anteroposterior or the right anterior oblique projection, whichever is appropriate, can be employed.

We would like to thank Dr. Simon Godfrey for his help in organizing the computer programme; and Dr. R. Gibson and Dr. M. Honey for allowing us to study patients under their care.

\section{References}

Arvidsson, H. (196r). Angiocardiographic determination of left ventricular volume. Acta Radiologica, 56, 321 .

Arvidsson, H. (1966). Angiocardiographic measurements in congenital heart disease. III. Size of left ventricle including analysis of normal ventricular volume in systole and diastole. Acta Radiologica. Diagnosis, 4, 155.

Bartle, S. H., Sanmarco, M. E., and Dammann, J. F., Jr. (1965). Ejected fraction: an index of myocardial function. American fournal of Cardiology, 15, 125. 
Braunwald, E., Fishman, A. P., and Cournand, A. (1956). Time relationship of dynamic events in the cardiac chambers, pulmonary artery and aorta in man. Circulation Research, 4, 100.

Braunwald, E., and Ross, J. (I963). Editorial. The ventricular end-diastolic pressure: appraisal of its value in the recognition of ventricular failure in man. American fournal of Medicine, 34, 147.

Bunnell, I. L., Grant, C., and Greene, D. G. (1965). Left ventricular function derived from the pressurevolume diagram. American fournal of Medicine, 39, 881.

Carlisle, R., Grant, C., Bunnell, I., and Greene, D. G. (1964). Pressure-volume loops of the human left ventricle from one-plane cineangiogram. Clinical Research, 12, 440.

Chapman, C. B., Baker, O., Reynolds, J., and Bonte, F. J. (1958). Use of biplane cinefluorography for measurement of ventricular volume. Circulation, 18, 1105.

Dodge, H. T., and Baxley, W. A. (1968). Hemodynamic aspects of heart failure. American fournal of Cardiology, 22, 24.

Dodge, H. T., and Baxley, W. A. (1969). Left ventricular volume and mass and their significance in heart disease. American fournal of Cardiology, 23, 528.

Dodge, H. T., Sandler, H., Ballew, D. W., and Lord, J. D., Jr. (1960). The use of biplane angiocardiography for the measurement of left ventricular volume in man. American Heart fournal, 60, 762 .

Dodge, H. T., Sandler, H., Baxley, W. A., and Hawley, R. R. (1966). Usefulness and limitations of radiographic methods for determining left ventricular volume. American fournal of Cardiology, 18, 10.

Falsetti, H. L., Mates, R. E., Greene, D. G., and Bunnell, I. L. (1970). Maximal contractile element velocity (Vmax) as an index of contractile state in man. (Abstract.) American fournal of Cardiology, 25, 94.

Grant, C., Greene, D. G., and Bunnell, I. L. (1965). Left ventricular enlargement and hypertrophy: a clinical and angiocardiographic study. American Fournal of Medicine, 39, 895 .

Greene, D. G., Carlisle, R., Grant, C., and Bunnell, I. L. (1967). Estimation of left ventricular volume by one-plane cineangiography. Circulation, 35, 61.

Hermann, H. J., and Bartle, S. H. (I968). Left ventricular volumes by angiocardiography: comparison of methods and simplification of techniques. Cardiovascular Research, 2, 404.

Hermann, H. J., Singh, R., and Dammann, J. F. (1969). Evaluation of myocardial contractility in man. American Heart fournal, 77, 755.
Hood, W. P., Rackley, C. E., and Rolett, E. L. (I968a). Ejection velocity and ejection fraction as indices of ventricular contractility in man. Circulation, 38, Suppl. 6, ror.

Hood, W. P., Rackley, C. E., and Rolett, E. L. (1968b). Wall stress in the normal and hypertrophied human left ventricle. American fournal of Cardiology, 22, 550.

Jones, J. W., Rackley, C. E., Bruce, R. A., Dodge, H. T., Cobb, L. A., and Sandler, H. (1964). Left ventricular volumes in valvular heart disease. Circulation, 29, 887.

Kennedy, J. W., Baxley, W. A., Figley, M. M., Dodge, H. T., and Blackmon, J. R. (1966). Quantitative angiocardiography. I. The normal left ventricle in man. Circulation, 34, 272.

Kennedy, J. W., Twiss, R. D., Blackmon, J. R., and Dodge, H. T. (1968). Quantitative angiocardiography. III. Relationships of left ventricular pressure, volume, and mass in aortic valve disease. Circulation, 38, 838.

Miller, G. A. H., Kirklin, J. W., and Swan, H. J. C. (I965). Myocardial function and left ventricular volumes in acquired valvular insufficiency. Circulation, 3I, 374 .

Miller, G. A. H., and Swan, H. J. C. (1964). Effect of chronic pressure and volume overload on left heart volumes in subjects with congenital heart disease. Circulation, 30, 205.

Moore, D. (1965). Simple assessment of left ventricular function during cardiac catheterization in children. Circulation, 32, Suppl. 2, 153.

Sandler, H., and Dodge, H. T. (1968). The use of single plane angiocardiograms for the calculation of left ventricular volume in man. American Heart Fournal, 75, 325.

Sandler, H., Hawley, R. R., Dodge, H. T., and Baxley, W. A. (1965). Calculation of left ventricular volume from single plane (A-P) angiocardiograms. (Abstract.) fournal of Clinical Investigation, 44, I094.

Sanmarco, M. E., and Bartle, S. H. (1964). Left ventricular volume determinations: comparison of angiocardiographic and thermal washout techniques. (Abstract.) Circulation, 30, Suppl. 3, 151.

Sutton, G. Chatterjee, K., and Miller, G. (I97I). Haemodynamic findings after homograft replacement of mitral valve. In Proceedings of the British Cardiac Society. British Heart fournal, 33, I42.

Vogel, J. H. K., Horgan, J. A., and Strahl, C. (1970). Left ventricular dysfunction in chronic constrictive pericarditis. (Abstract.) American fournal of Cardiology, 25, 134 . 